\title{
Characterization of Pipe Bomb Fragments using Optical Microscopy and Scanning Electron Microscopy
}

\author{
M.J. Platek,* O. J. Gregory,** T. Duarte,**J. Oxley, *** J. Smith ***, E. Bernier*** \\ *Department of Electrical, Computer \& Biomedical Engineering, University of Rhode Island, \\ Kingston, RI 02881 \\ **Department of Chemical Engineering, University of Rhode Island, Kingston, RI 02881 \\ ***Department of Chemistry, University of Rhode Island, Kingston, RI 02881
}

One of the most commonly used improvised explosive devices (IED) is the pipe bomb. Readily accessible materials combined with the simplicity in construction makes this explosive device one of the most desirable devices to inflict damage to a given target. Extensive work has been done correlating the fragment size to the type of propellant used in the pipe bomb [1]. At most crime scenes where a pipe bomb is used, there is little evidence left on the pipe bomb fragments as to what type of propellant was used. Therefore, additional studies were performed to correlate microstructure of the fragments to the type and energy of propellant was used in the device [2]. The two methods used for this study involved the use of an optical microscope (Nikon Optiphot) and a scanning electron microscope (JEOL 5900 LV with PGT EDS) to correlate certain microstructural features such as pearlite deformation, ferrite deformation, shear bands and twining with propellant energy.

The type of pipe bomb used in the study was a galvanized, schedule 40 pipe that was approximately 2 inches inner diameter and 12 inches long, Figure 1. The propellants used were black powder, red dot, bullseye, winchester, IMR. After detonation, the fragments were collected and cataloged according to size. Approximately 60 different pipe bombs were detonated under various conditions (end cap detonation, center detonation of fully loaded pipes and partially loaded pipes) and about $87 \%$ of the pipe bomb was recovered after detonation. An example of the type of fragments that were recovered is shown in Figure 2. Selected the pipe bomb fragments were mounted in an Extec ${ }^{\circledR}$ two part epoxy such that the cross section of the fragment could be analyzed. Each sample was polished with 240, 400, 600 and 1200 grit SiC paper. A final polishing step using 3 um alumina and 0.3 um alumina slurry was performed. Samples were etched in $2 \%$ nital to delineate the microstructure and immediately examined with both types of microscopes. One of the challenges working with this material is corrosion that forms after a short period of time. Using optical microscopy, the changes in the ferrite and pearlite phases could be identified and correlated to type of propellant was used in the pipe bomb. An example of the optical images captured is shown in Figure 3. With very high energy propellants, the fragment showed higher incidents of twining. Scanning electron microscopy of the fragments shown in Figure 4, more detail of the deformed pearlite phase.

The combination of scanning and optical microscopy proved to be a valuable combination of tools in correlating the microstructure to the type of propellant used in the pipe bomb. This type of examination requires only several fragments from the scene of an incident and can be performed in a relatively short period of time to aid law enforcement agencies identifying the class of explosive used. 


\section{References}

[1] Oxley, J. C.; Smith, J. L.; Resende, E.; Rogers, E.; Strobel, R. A.; Bender, E. C., Improvised Explosive Devices: Pipe Bombs. Journal of Forensic Sciences 2001, 46, (3), 87-110.

[2] Gregory, O.;Oxley, J.C.;Smith, J.; Platek, M.; Ghonem, H.; Bernier, E.;Downey, M.; Cumminsky, C, Microstructural Characterization of Pipe Bomb Fragments, Materials Characterization 2010 Jan. 4

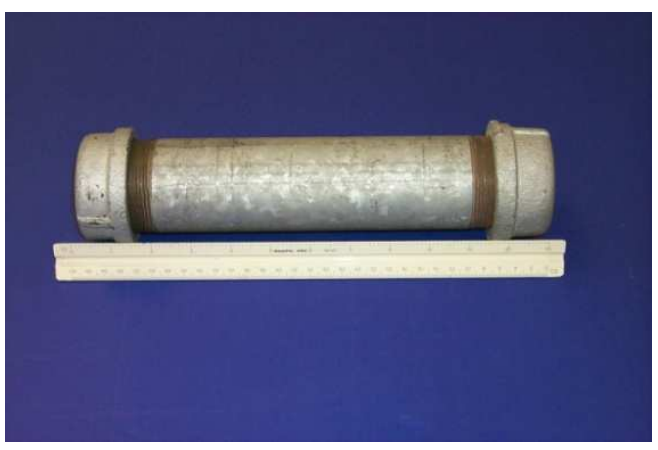

1. Example of pipe bomb used for study

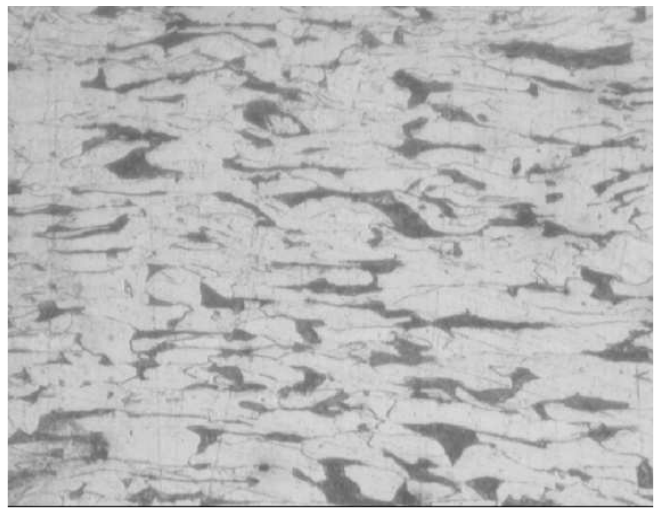

FIG. 3. Optical micrograph at 500x of red dot
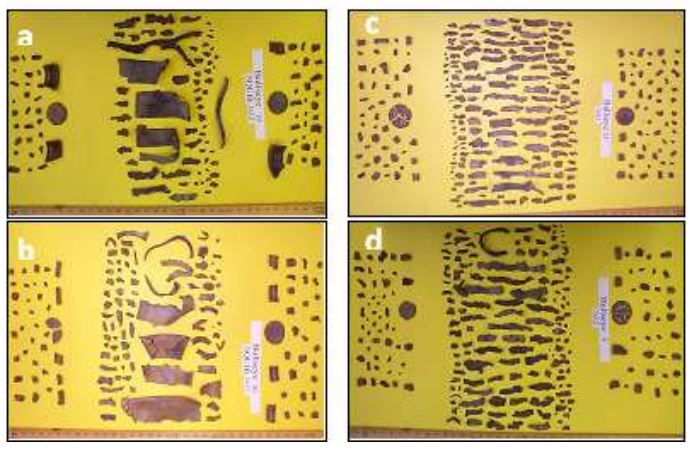

FIG. 2. Pipe bomb fragments using Bullseye with end cap and center detonation

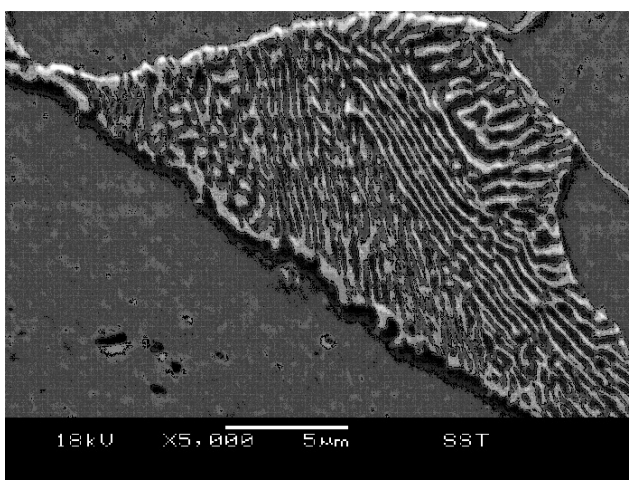

FIG. 4. SEM micrograph of pearlite phase 